اثر يارامترهاى خاك بر توليد اوليه سطح زمين در مراتع جمنزار فندوقلوى نمين

در استان اردبيل

اردوان قربانى '، الناز حسنزاده كوهساره'، مهدى معمرى'، كاظم هاشمى مجد`و اردشير يورنعمتى

(تاريخ دريافت:

جكيده

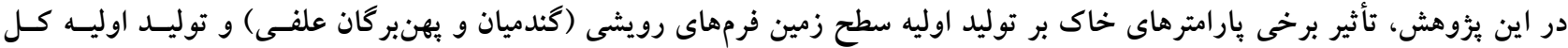

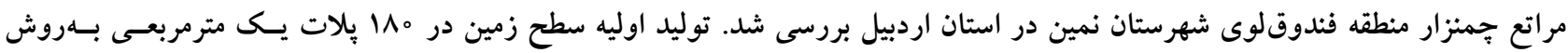

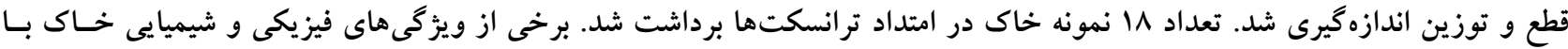

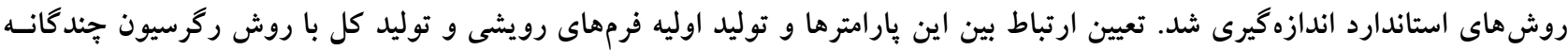

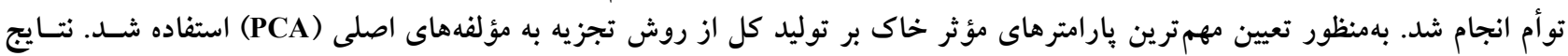

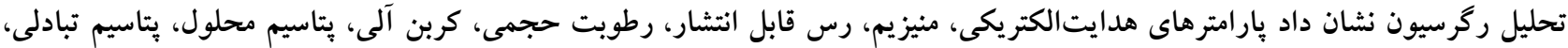

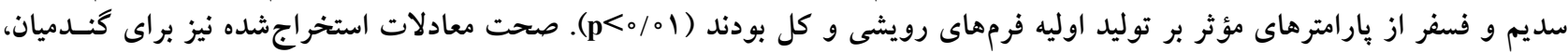

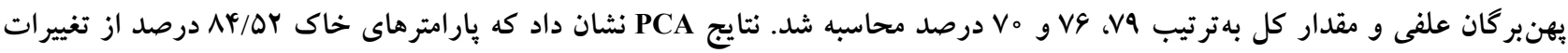

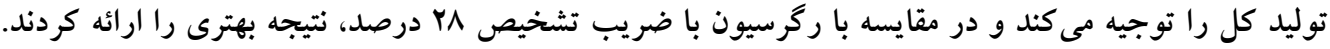

وازمهاى كليدى: مدلسازى توليد، زيست توده، فرم رويشى، بارامترهاى خاك، مراتع علفزار، شهرستان نمين

ا.كروه منابع طبيعى، دانشكده كشاورزى و منابع طبيعى، دانشگاه محقق اردبيلى

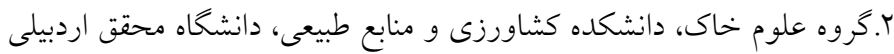

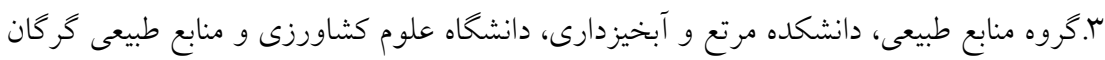

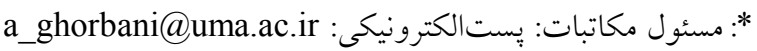


توليــ گنــدميان از عامـل رطوبـت حجمسى خـاى اسـتفاده و

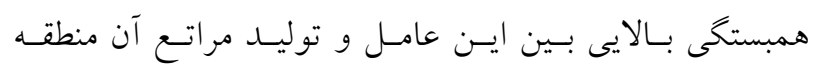

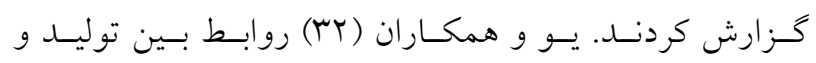

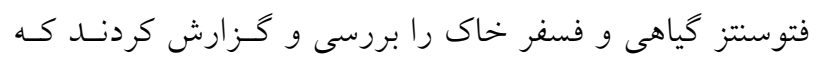

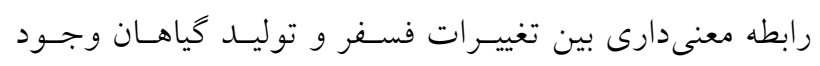

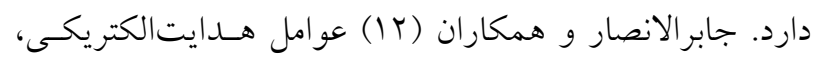

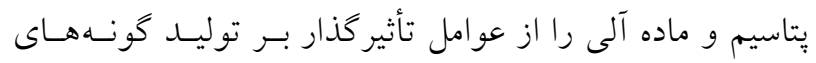

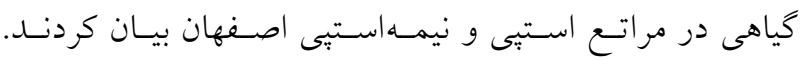

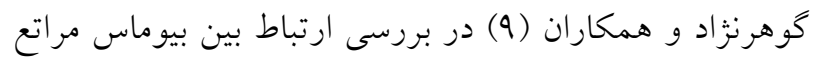

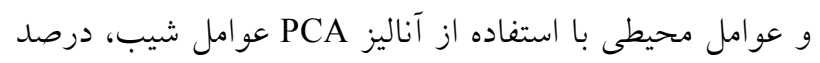

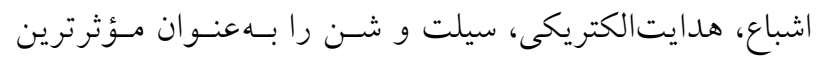

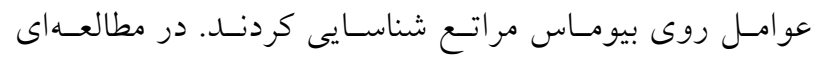

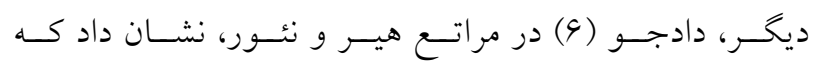

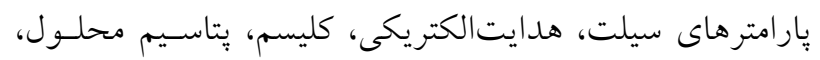

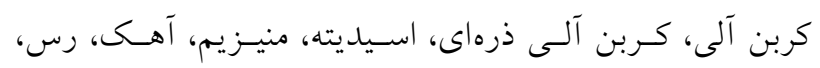

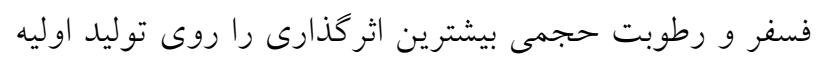
سطح زمين دارند. مراتع جمنزار منطقه فندوق لوى شهرستان نمسين در اسـتان اردبيل بهدليل وجود يوشش كياهى منحصربه فرد از كونههـاى

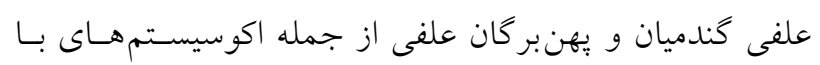

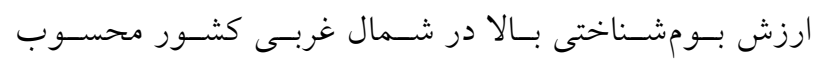

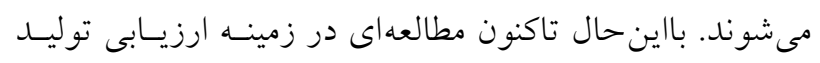

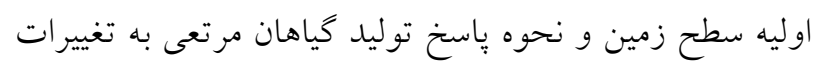

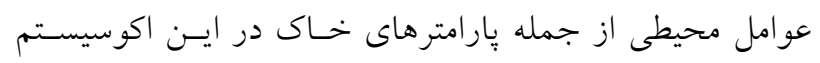

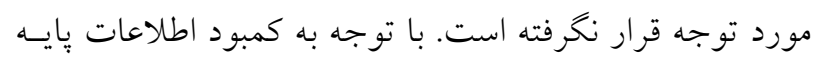

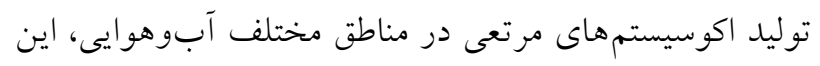

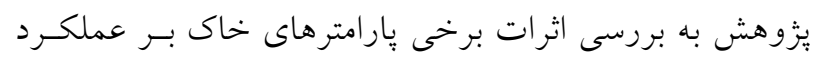

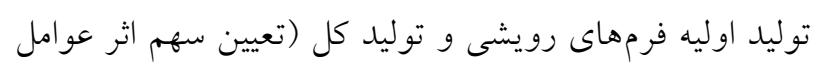

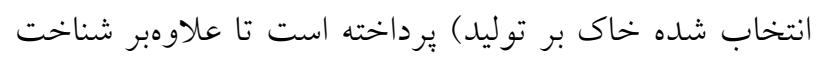

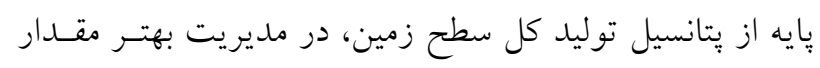

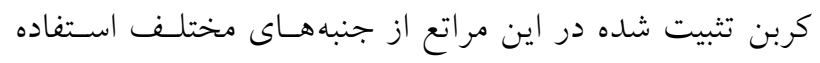

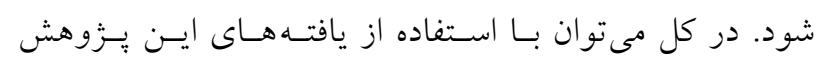

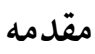

در يك اكوسيستم، توليدات گياهى، مقدار انرزى قابل دسترس براى مصرف كننده و تجزيه كنندهها را تعيين مى كننـد؛ بنـابر اين شناخت روند تغييرات و عوامل مؤثر بر توليد اوليه، بيشزمينه

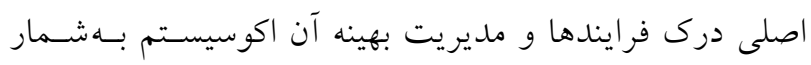

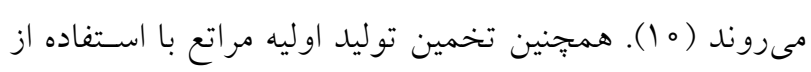

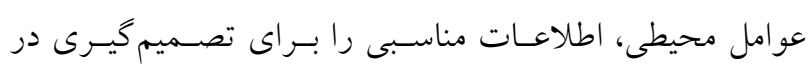
مورد نرخ خراى دام در ابتداى هر فصل جرايى در اختيار قرار

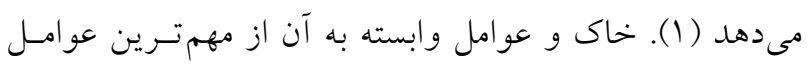

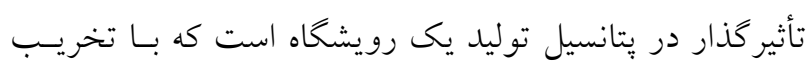

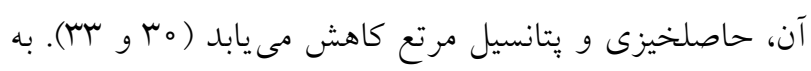

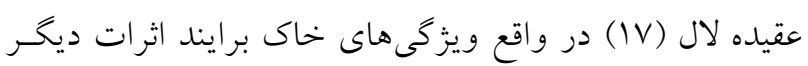

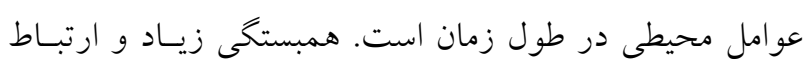

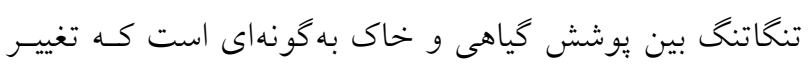

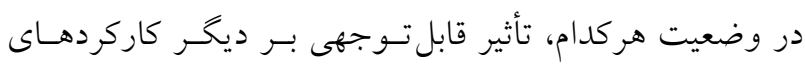

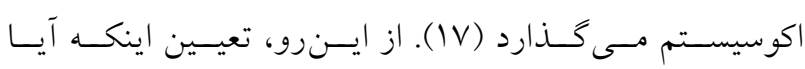

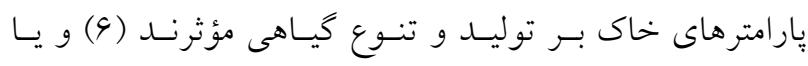

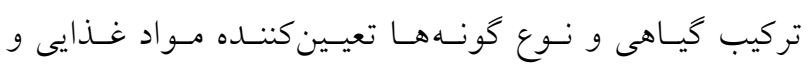

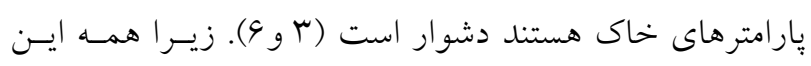

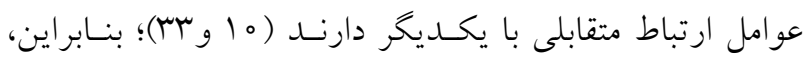

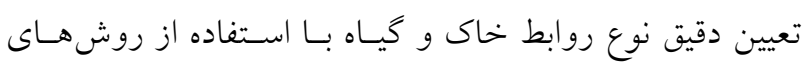

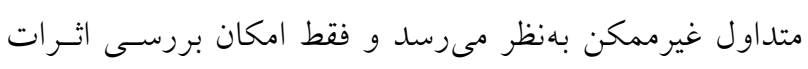

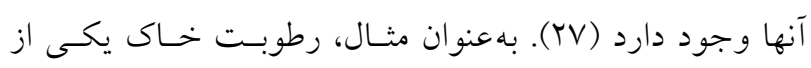

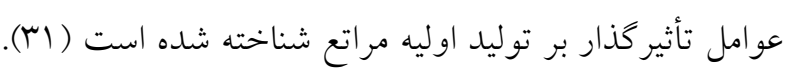

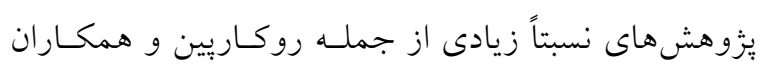

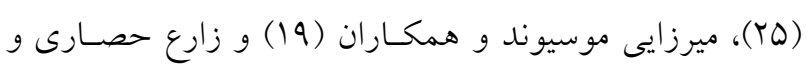

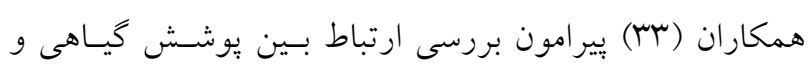

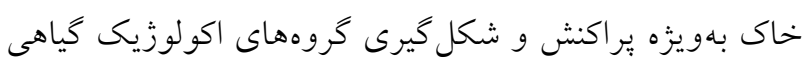

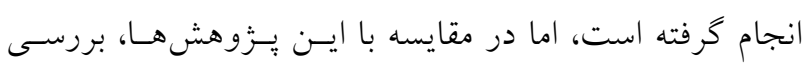

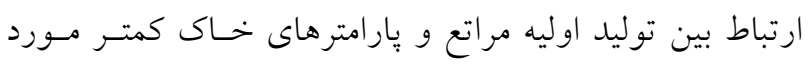

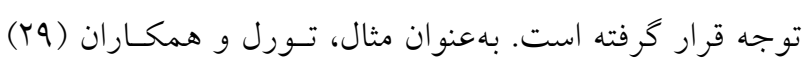

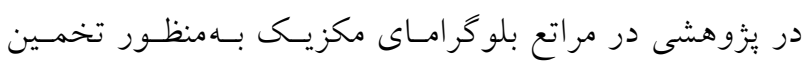




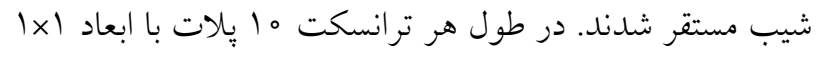

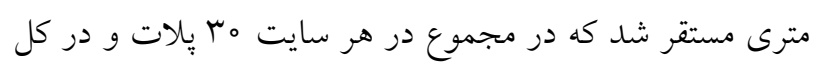

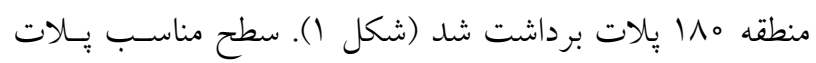

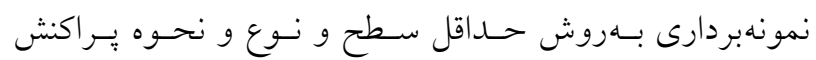

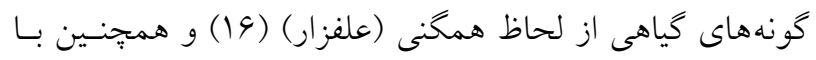

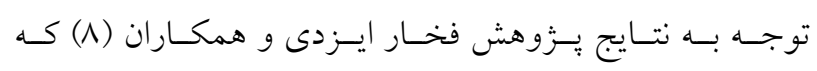
بِلاتهاى يـك مترمربعى را در مقايسـه داراى كمتـرين اشـتباه

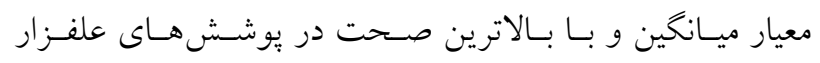
كزارش كردهاند، يكى مترمربع در نظر كرفته شد. ابعـاد و تعـداد

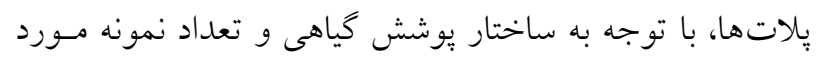

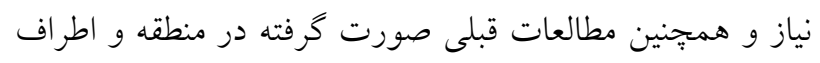

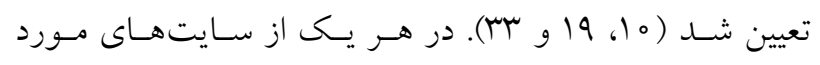

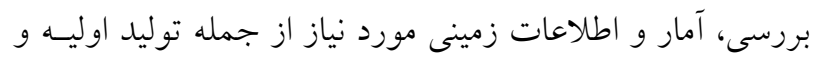

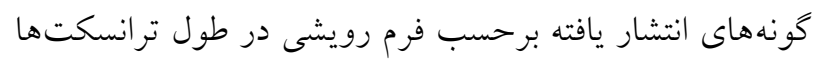

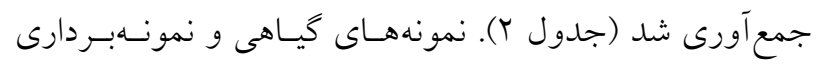

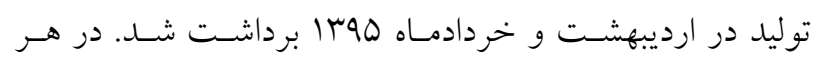

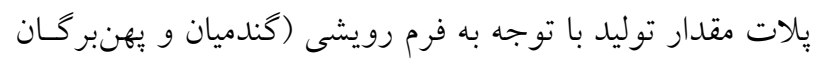

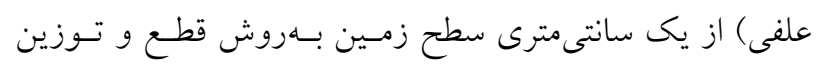

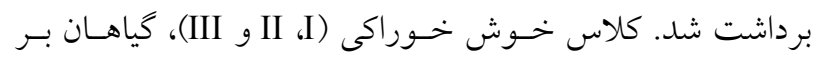

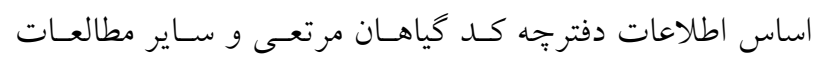

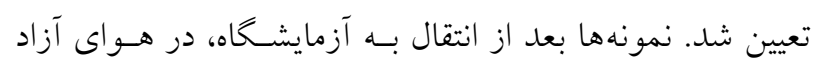

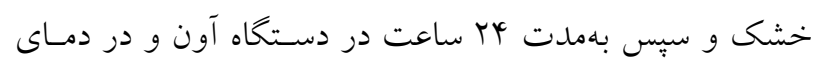

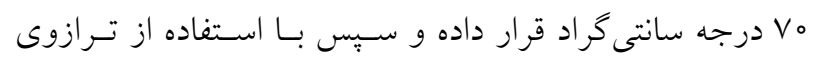

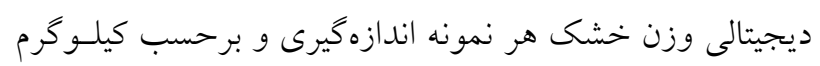
در هكتار محاسبه شد.

\section{نمونهبردارى و آزمايشهاى خاى}

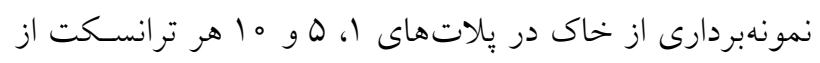

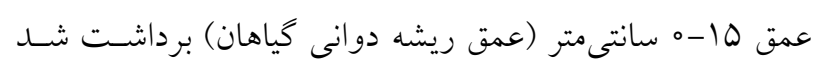

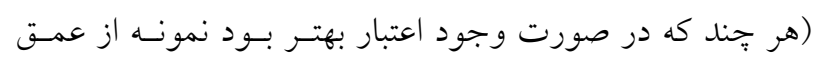

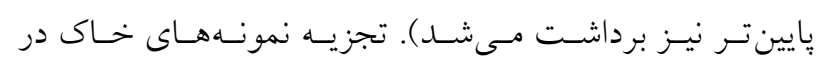

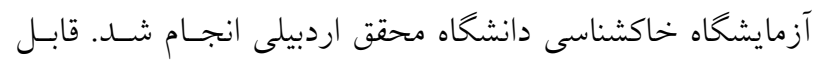

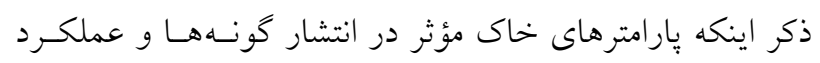

به عنوان دادههاى بِايه، بهمنظور تعيسين ظرفيـت جـــاى مراتـع

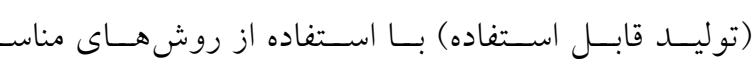
توسعهيافته اقدام كرد.

\section{مواد و روشها - ماد}

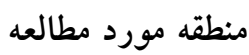

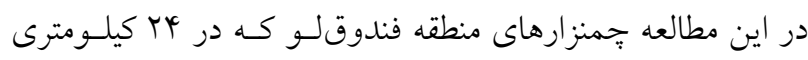

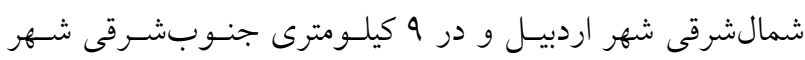

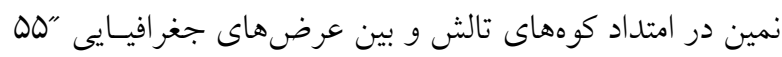
r

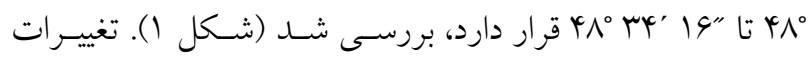

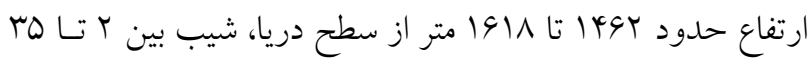

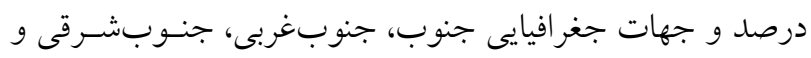

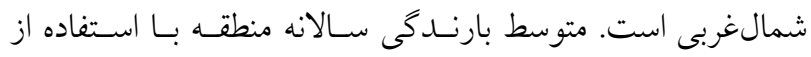

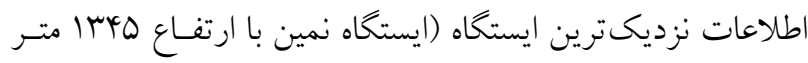

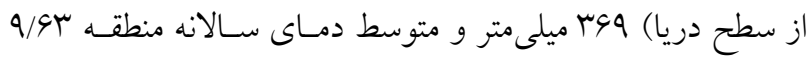

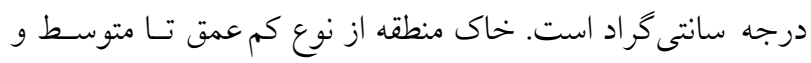

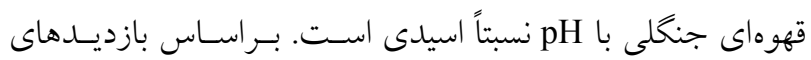

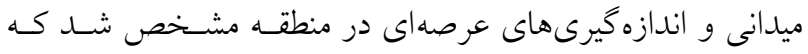

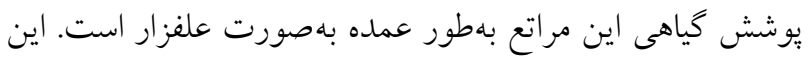

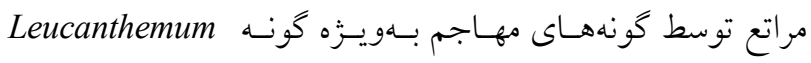

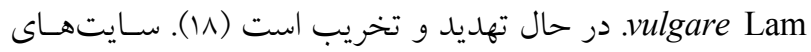

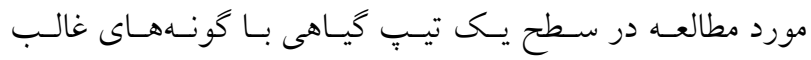
،Trifolium pratense L. Leucanthemum vulgare Lam. Vulpia g.Leontodon hispidus L. ‘Trifolium repense L. myuros L. نمونهبردارى از توليد اوليه سطح زمين

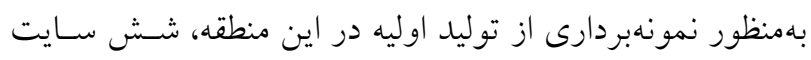

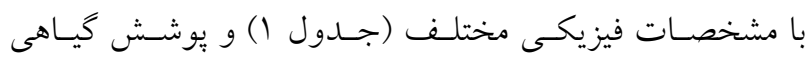

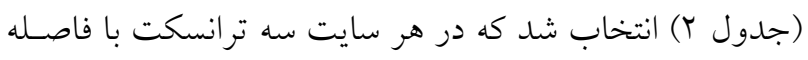

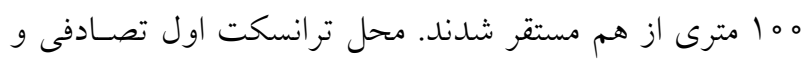

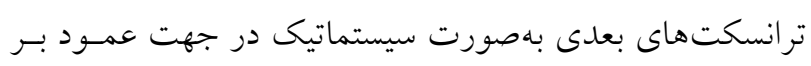




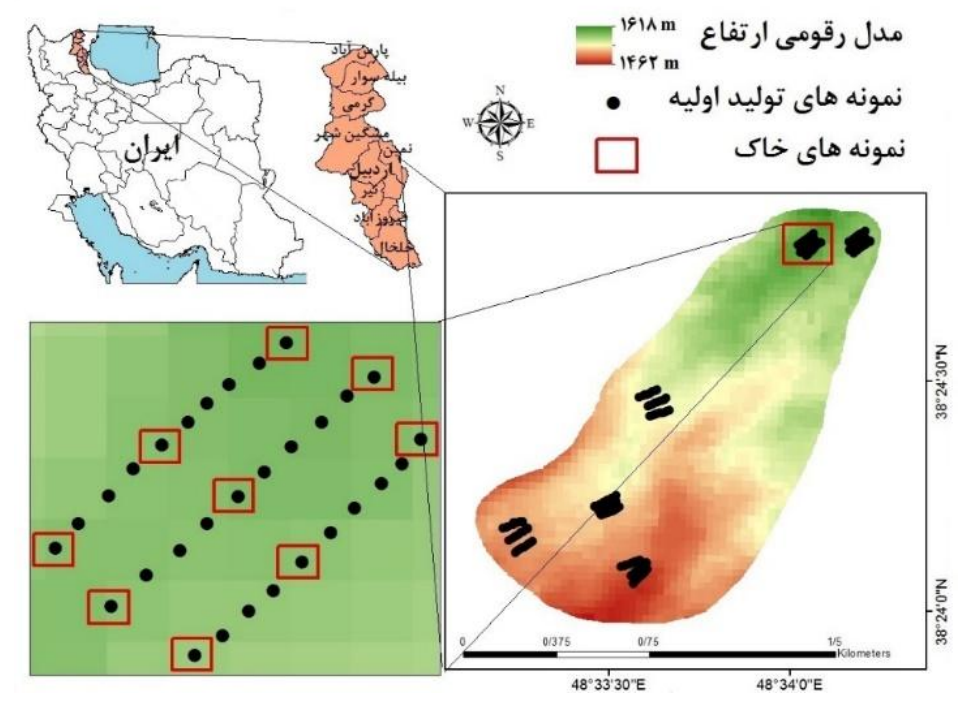

شكل 1. موقعيت منطقه مورد مطالعه در سطح كشور، استان اردبيل و شهرستان نمين و موقعيت بِلاتهاى نمونهبردارى توليد اوليه و خاك

جدول ا. مشخصات فيزيكى سايتهاى نمونهبردارى شده (ميانخين \ انحر اف معيار)

\begin{tabular}{|c|c|c|c|c|c|c|}
\hline سايت 9 & سايت ه & سايت r & سايت r & سايت r & سايت 1 & عوامل \\
\hline $10 \wedge 9 \pm Y / \circ 9$ & $1901 \pm Y / 00$ & $10 r Y \pm r / 99$ & $10 \Delta \Gamma \pm \Gamma / \Lambda r$ & $\mid r q 4 \pm \Delta / \circ r$ & $1011 \pm 1 / 9 r$ & ارتفاع (m) \\
\hline 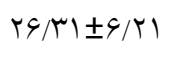 & $r \mid / r T \pm Y / r T$ & $|Y / q| \pm r / N \mid$ & $11 / V \Delta \pm r / 1 r$ & 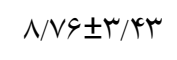 & $|4 /| 4 \pm 9 / 1 \mid$ & شيب (.) \\
\hline جنوب شرقى & جنوب غربى & جنوب شرقى & شمال غربى & جنوب غربى & جنوب & جهت \\
\hline لومى لو & لومى لو لو & لومى شنى & لومى شنى & لومى لو لو & لومى & بافت خاك \\
\hline
\end{tabular}

مرحله انجام گرفت. بافت خاك (شن، سيلت و رس) بهروش

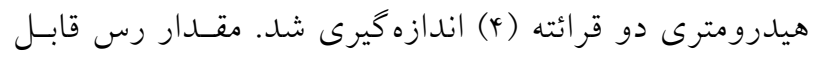

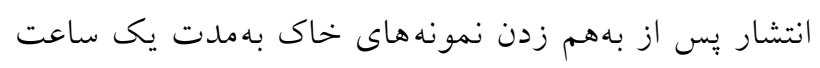

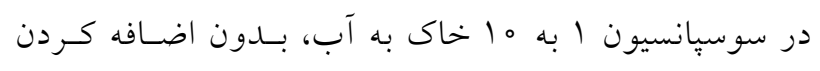

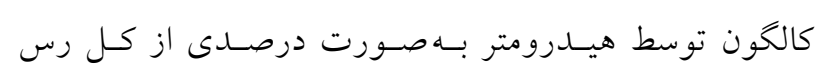

موجود در خاك اندازهكيرى شد (ه).

تجزيه و تحليل آمارى

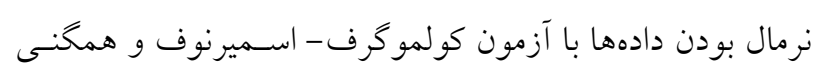

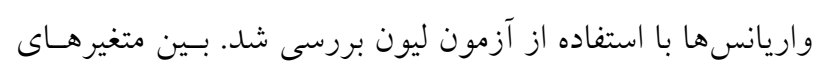

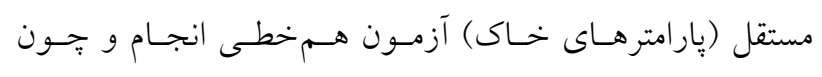

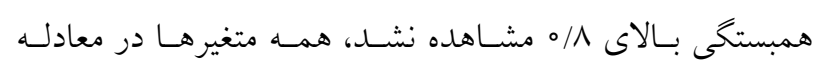

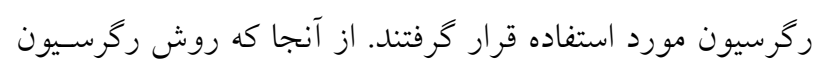

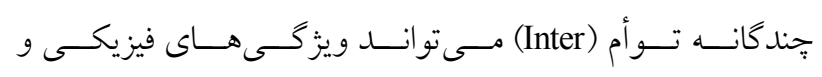

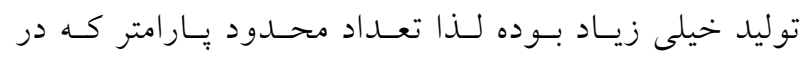

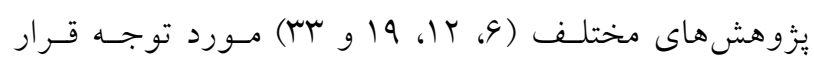

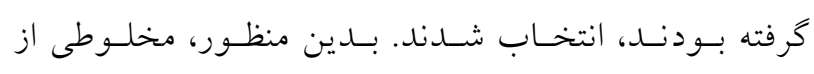

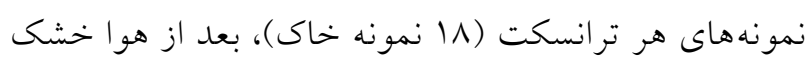

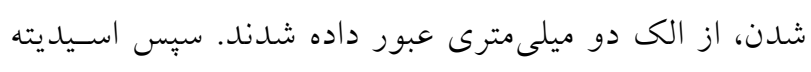

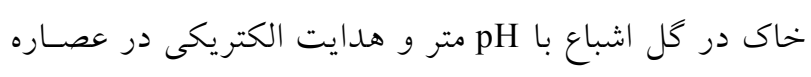

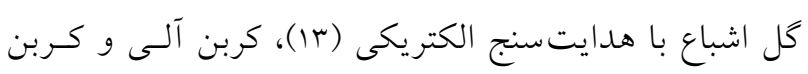

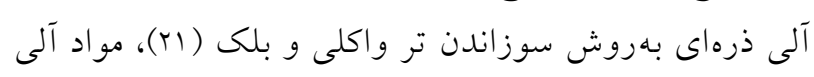

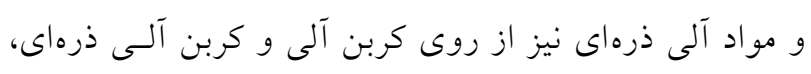

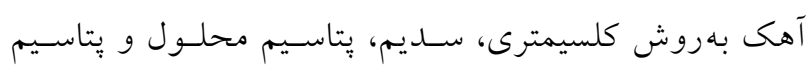

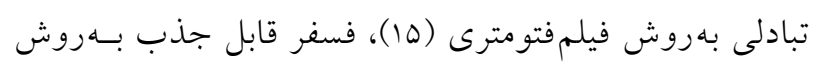

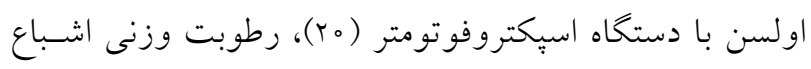

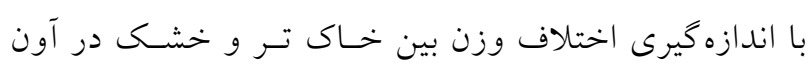

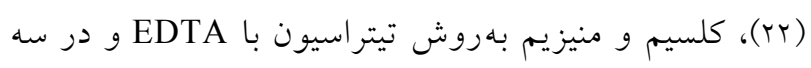


جدول r. گونههاى موجود در طبقات ارتفاعى مختلف، خوشخوراكى و فرم رويشى شناسايى شده

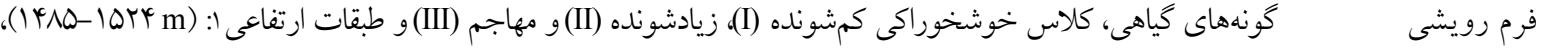

$(1090-1904 \mathrm{~m}) \mathrm{r}$. $(10 \mathrm{TO}-109 \mathrm{Y} \mathrm{m}): \mathrm{r}$

Leucanthemum vulgare Lam. (1, 2, 3, III), Trifolium repense L. (1, 2, 3, I), Trifolium pratense L. (1, 2, 3,

I), Trifolium micranthum Viv. (1, 2, 3, I), Cerastium glomeratum Thuill. (1, 2, 3, III), Leontodon hispidus

L. (1, 2, 3, III), Alchemilla caucasia. (1, 2, 3, I), Taraxacum syriacum Boiss. (1, 2, 3, III), Luzula Multiflora

(Ehrh) Lej. (1, 2, 3, III), Galium verum L. (1, 2, 3, III), Fragaria vesca L. (1, 2, 3, I), Aster alpinus L. (1, 2,

3, III), Hypericum linarioides Bosse. (1, 2, 3, I), Eryngium billardierei F. Delaroche. (1, 2, 3, III),

Sanguisorba minor Scope. (1, 2, 3, I), Rumex tuberosa L. (1, 2, 3, III), Myosotis alpestris (1, 2, 3, III),

Barbarea minor C. Koch. (1, III), Achillea millefolium L. subsp .millefolium (1, 2, 3, III), Sedum lenkoranicum Grossh. (1, III), Stachys byzantina K. Koch. (1, 2, 3, III), Cirsium vulgare (Savi) Ten. (1, 3, III), Senecio vulgaris L. (1, 2, 3, III), Carum carvi L. (1, 2, 3, III), Medicago sativa L. (1, I), Chenopodium foliosum (Mench) Aschers. (1, III), Carex divulsa Gaudin. (1, 2, III), Tripleurospermun disciforme (C.A.Mey) Schultz-Bip. (1, III), Scariolla orientalis (Boiss).Sojak. (1, 2, 3, II), Ranunculus millefolius Banks \& Soland. (1, 3, I), Trifolium compestre Schreb. (1, 2, 3, I), Geranium molle L. (1, 2, 3, III), Prunella vulgaris L. (1, 2, 3, III), Equisetum arvense L. (1, III), Cardaria draba L. Desv. (1, 2, III), Cruciata pedomontana Bellardi. (1, 2, 3, III), Carex songarica Kar. \& Kir. (1, III). Plantago Lanceolata L. (1, 2, 3, III), Hieracium matrense N.P. (1, 2, 3, III), Vicia cracca L. (1, 2, 3, I), Ranunculus constantin opolitanus DC. (2, 3, I), Vulpia myuros (L.) J. F. Gmel. (2, 3, I), Veronica arvensis L. (2, 3, III), Hypericum perforatum L. (2, 3, I), Barbarea plantaginea DC. (2, III), Galium aparine L. (2, III), Silene latifolia Poir. Subsp. (2, III), Primula macrocalyx Bunge. (2, 3, III), Dianthus orientalis Donn. (2, 3, III), Veronica gentianoides Vahl. (2, 3, III), Lathyrus sativus L. (2, I), Anthriscus sylvestris L. Hoffm. (2, III), Phoupsis stylosa (Trin). (2, 3, III), Plantago major L. (2, III), Hypericum tetrapterum Fries. (2, 3, I), Hieracium pilosella L. (2, 3, III), Draba nemorosa L. (2, 3, III), Arenaria leptoclados (Riechenb) Guss. (2, 3, III), Cirsium sp. (2, 3, III), Lotus corniculatus L. (2, 3, I), Polygala anatolica Boiss \& Holder. (3, III), Asperula setosa Jaub. \& spach. (3, III), Erodium cicutarium (Jusl.) L. Her. Ex Aiton. (3, II), Vicia sativa L. (3, I), Convolvulus arvensis L. (3, II), Prunella laciniata L. (3, III), Potentilla argentea L. (3, I), Filago vulgaris Lam. (3, III).

Poa bulbosa L. (1, 2, II), Poa pratensis L. (1, 2, 3, II), Potentilla adscharica Sommier \& Levier ex keller. $(1,2,3$, I), Bromus briziformis Fisch. \& C. A. Mey. (1, I), Trisetum flavescense L. (1, 2, 3, II), Dactylis glomerata L. (1, 2, 3, I), Hordeum bulbosum L. (1, 2, I), Lolium rigidum Gaudin. (1, 2, I), Bromus scoparius L. (1, 2, 3, I), Poa trivialis L. (2, 3, II), Cynosurus echinatus L. (2, 3, I). Avena byzantina K. Koch. (3, II).

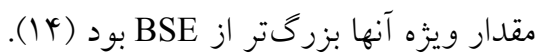

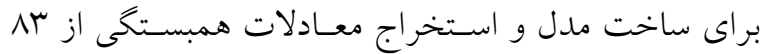

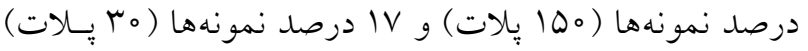
براى ارزيابى صحت مدل مـورد اسـتفاده قــرار كرفـت. بـراى بررسى صحت معادلات، تعداد هم يِلات بهعنوان نقاط كتــرل در معادله جايخذارى شده و با اطلاعات نقاط زمينسى بررسى بـ شد و درنهايت تعداد نقاطى كه توسط معسادلات توليـد اوليـه سطح زمين بهطور صحيح تبيـين شـده بودنــد و بــا اطلاعـات زمينى هماهنكى داشتند، شمارش شدند و بر كل نقـاط كنتـرل انتخاب شده تقسيم شد. بدين ترتيب نسبت صحت طبقهبندى محاسبه شد. - ماس. نتايج در محدوده مورد مطالعه و در سطوح يلاتهـاى نمونـهبــردارى

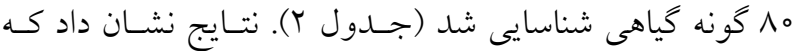

شيميايى مؤثر بر توليد اوليه كل و فـرمهـاى رويشسى را رتبـهبنــى

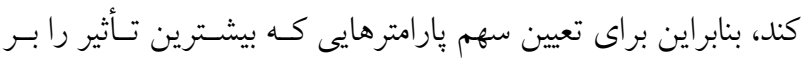
توليد اوليه سطح زمين داشتند، از اين روش استفاده شد (روشهاى مختلف استفاده شد، اما بهترين نتايج با درصد R بـالا از ايسن روش بهدست آمد). در اين روش توليد اوليه سطح زمين فرمهاى رويشى و كل بهعنـوان متغيـر وابسـته و ويزخى هــاى فيزيكسى و شـيميايى اندازهيرى شده خاى بهعنوان متغير مستقل در نظـر كرفتـه شــند. فرمول عمومى معادله رگرسيون جندگانه بهصورت زير است: $\mathrm{Y}=\mathrm{a}+\mathrm{b}, \mathrm{x}_{1}+\mathrm{x}_{\mathrm{n}}+\cdots+\mathrm{b}_{\mathrm{n}} \mathrm{b}_{\mathrm{r}} \mathrm{X}_{\mathrm{r}}$

كه در آن: Yقدار بيش بينى شــده متغيـر وابســه (Y)، a: مقـدار ثابت (constant)، b: ضريب ركرسـيون و x: مقـادير متغيّرهـاى مستقل است. علاوهبر تحليل رگرسيون، بـهعلـت قابليـت روش

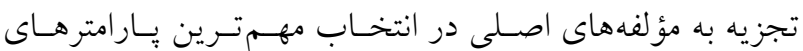

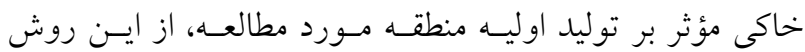
استفاده شد. در اين روش مؤلفهها تا آنجايى انتخاب شــنـد كـهـ 
ديخرى مانند عوامل تويوكرافى، اقليمى و سـاير عوامـل نيـز در

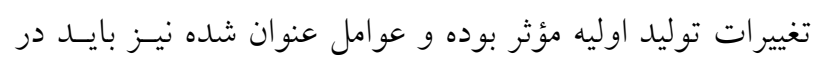

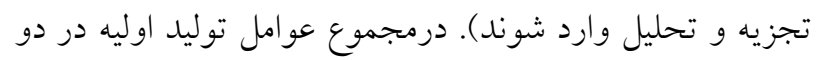

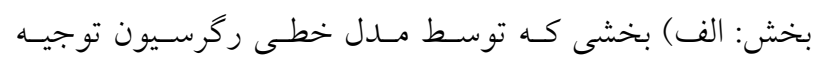

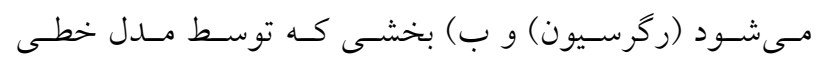

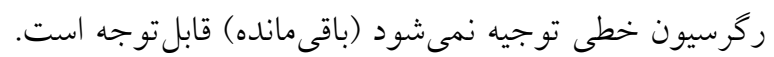

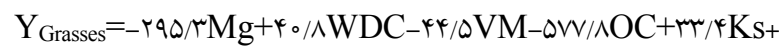
$V / \Delta, \mathrm{Na}-1 \circ Y / Y$ Kexch-IV०VI/\&P $\mathrm{R}^{r}=0 \cdot \%$

$\mathrm{Y}_{\text {Forbs }}=-1094 / 0 \curlyvee E C-\eta \Gamma / / \mathrm{WDC}+\Delta \Delta / / \mathrm{VM} \quad \mathrm{R}^{r}=\kappa r \%$

$\mathrm{Y}_{(\mathrm{P} \text { Total })}=-|V| r / \circ \varphi \mathrm{EC}+r r / r \mathrm{Ks}+q / \varphi \mid \mathrm{Na} \quad \mathrm{R}^{r}=r \Lambda \%$

كه در اين معادلات: EC: هدايتالكتريكى، OC: كربن آلى، Mg:

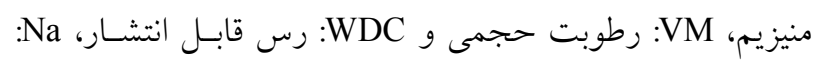

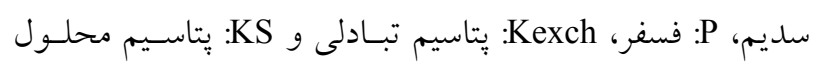

هستند.

درنهايت صحت معـادلات، بـا اسـفناده از روش ذكـر شـده محاسبه شد كه بهترتيب V9، V9 و Do درصد براى توليـد اوليـه

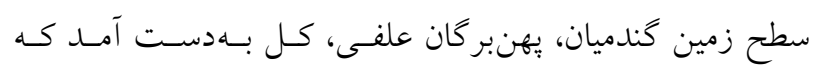
نشاندهنده اعتبار مدل است.

در جــدول ومقـادير ويـزّه و درصـــ واريـانس هريـك از مؤلفهها آمده است. با توجه به مقادير ويزه و شـاخص BSE در مؤلفههاى اول تا ششــم شـر ايط صـدق مسى كنــ (مقـدار ويـزّه

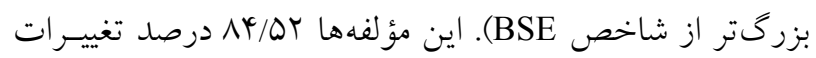
توليد گياهان مرتعى را در بر مى گيرد.

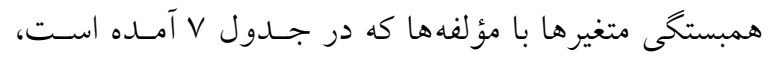
بيانكر آن است كه مؤلفه اول بهترتيب شامل كـربن آلى ذرهاى،

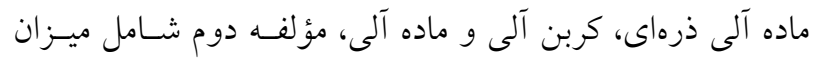
شن، سيلت، رس و اسيديته، مؤلفه سوم شامل بِّاسـيم محلـول،

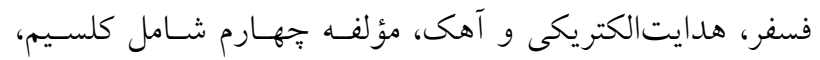
سديم و رطوبت حجمى، مؤلفه بــنجم شـامل يتاسـيم تبـادلى و مؤلفه ششم شامل منيزيم و رس قابل انتشار است. بنابراين، ايسن عوامل به ترتيب با توجه به تأثير بالاى خود بـهـعنـوان مـؤثرترين يارامترهاى خاى در تغيير توليد اوليه مراتع منطقه مورد مطالعـه شناسايى شدند.
حدود هم درصد از كل گياهان را يهنبر گان علفس، ها درصــ باقىمانده را گُندميان تشكيل مىدهند. در حالت كلى در مجموع

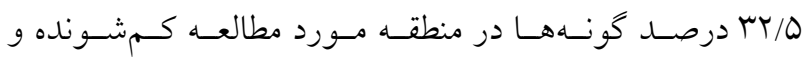
خوش خوراك، ه 1 درصد زيادشونده و OV/D درصد كونسهــاى مهاجم هستند كه نشانخر تخريب تركيب گياهى است. برخى از ويزّى هاى فيزيكى و شيميايى خاكهاى مورد مطالعه

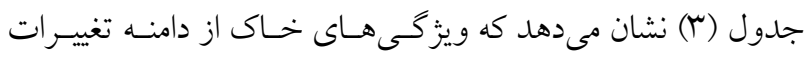

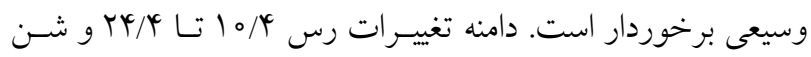

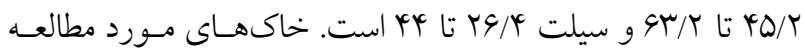

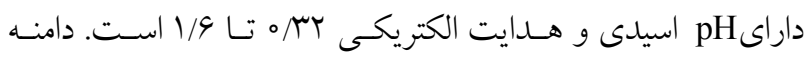

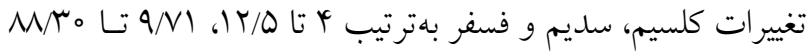
و ro/ تا 19/ه است. مقدار كل كربن آلى و ماده آلى در خاكهاى

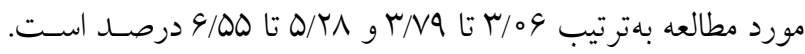

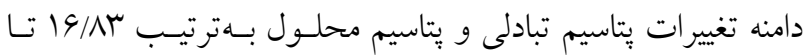
r جدول (†) خلاصه مدلهاى رگرسيونى توليـد اوليـه كـل و توليد اوليه فرمهاى رويشى با بار امترهاى خاى را نشان مىدهد. در اين جدول مقدار R بيانكننده ميزان همبستكى بين متغيرهاى مستقل و وابسته اسـت و ضـريب تشـخيص R هـــم مشـخص مى كند كه جهه مقــدار از واريـانس متغيــر وابسـته بـهـ متغيرهــاى مستقل مربوط است. همان كونه كه در هدف اين يـزّوهش بيـان

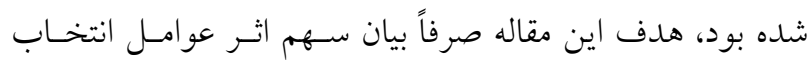
شده خاك بوده است، لذا با توجه به نتايج ب ب درصـد تغييـرات توليد اوليه كُندميان، أ| درصد تغييرات توليد اوليسه بهــنبركـان علفى و سب درصد تغييرات توليد اوليه كل، توسـط پِارامترهـاى انتخاب شده خاك، توجيه شده است. در جدول (ه) آناليز واريانس ارتباط بين توليد اوليـه كـل و فرمهاى رويشى با يارامترهاى خاى ارائه شده است. با توجه بــ ستون معنى دارى آمارى مدل ركرسـيون مشـاهده شـــ كـهـ بـين توليد اوليه كل و فرمهاى رويشـى بـا پار امترهـاى خــاك رابطـهـ خطى و معنسى به كاررفته بيش بينى كننده مناسبى براى متغير توليـــ اوليـه سـطح

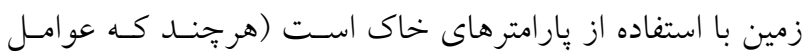




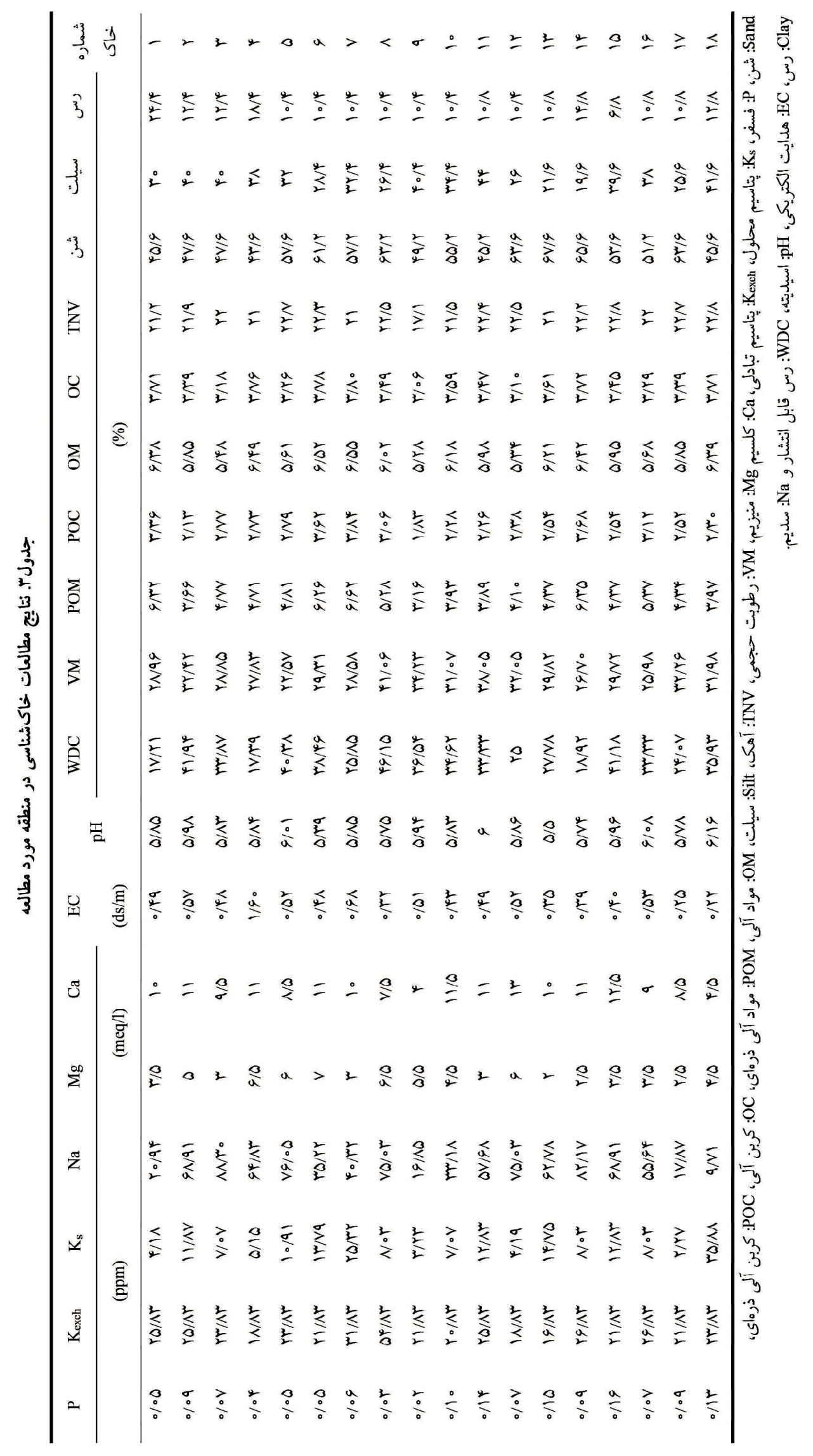


جدول ثا. ضريب تشخيص رابطه رگرسيونى توليد اوليه كل و فرمهاى رويشى با يار امترهاى خاك

\begin{tabular}{|c|c|c|c|}
\hline$(\%) \mathrm{R}^{r}$ & $(\%) \mathrm{R}$ & خطاى معيار برآوردى & متغير \\
\hline Q० & V。 & FTV & توليد اوليه كندميان \\
\hline er & 94 & 949 & توليد اوليه يهنبر گان علفى \\
\hline rA & مr & 991 & توليد اوليه كل \\
\hline
\end{tabular}

جدول ه. آناليز واريانس مدل رگرسيون ارتباط بين توليد اوليه كل و فرمهاى رويشى با يارامترهاى خاك

\begin{tabular}{|c|c|c|c|c|}
\hline $\mathrm{F}$ & ميانخين مربعات & درجه آزادى (df) & آماره & متغير \\
\hline \multirow[t]{3}{*}{$1 \circ / V^{* *}$} & IVTAYGY & 10 & ركرسيون & \\
\hline & $19 \circ M Y$ & 194 & باقى مانده & توليد اوليه گندميان \\
\hline & - & 189 & كل & \\
\hline \multirow[t]{3}{*}{$\mathrm{V} / \mathrm{V} \mathrm{Q}^{* *}$} & MIFYGYO & 10 & ركرسيون & \\
\hline & $Y \circ \Delta V M r$ & 194 & باقى مانده & توليد اوليه بهنبر گان علفى \\
\hline & - & 189 & كل & \\
\hline \multirow[t]{3}{*}{$\varphi / \backslash \wedge^{* *}$} & INGAVYO & 10 & ركرسيون & \\
\hline & FYAVQq & 194 & باقى مانده & توليد اوليه كل \\
\hline & - & 189 & كل & \\
\hline
\end{tabular}

جدول 9. مقادير ويزه و واريانس مربوط به هر يك از مؤلفها در روش PCA

\begin{tabular}{|c|c|c|c|c|}
\hline BSE & واريانس تجمعى (\%) & واريانس توجيه شده (\%) & مقادير ويزه & مؤلفههـا \\
\hline$r / 4 q$ & $r Q / 94$ & $T Q / 94$ & $r / 9 T$ & 1 \\
\hline$r / 4 q$ & $41 / 94$ & $10 / 99$ & $T / \Lambda \Lambda$ & r \\
\hline $1 / 99$ & DS/FT & $14 / V G$ & $r / 90$ & $r$ \\
\hline $1 / 99$ & $99 / 94$ & $10 / 01$ & $1 / 19$ & 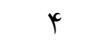 \\
\hline$|/ r|$ & VQ/r & $q / \varphi_{0}$ & $1 / 99$ & 0 \\
\hline $1 / 04$ & $\Lambda Y / \Delta r$ & $1 / 19$ & $1 / 4 V$ & 9 \\
\hline
\end{tabular}

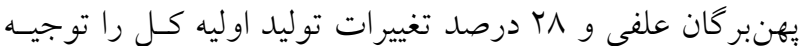
ميكند و بهنظر مىرسد علاوه بر عوامل خاك ساير عوامل مانــــ

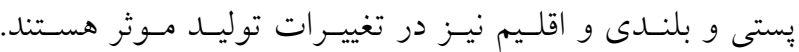

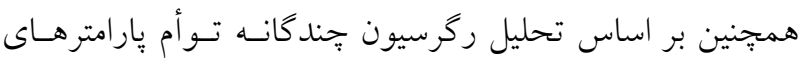
مورد بررسى با توليد اوليه نشان داد، متغيرهايى مانتــ اسـيديته،

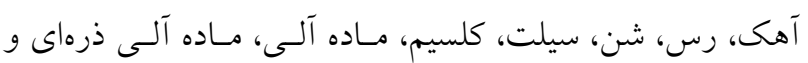
كربن آلى بهدليل اثر غيرمعنىدار بر توليد اوليـه سـطح زمسين از

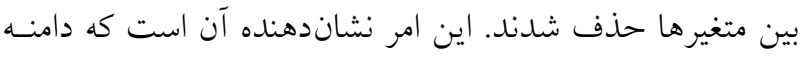

بحث و نتيجه كيرى

در اين يزٔوهش از مراتع جِمنـزار فنـدوق لـوى نمسين در اسـتان

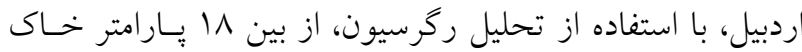
تعداد 9 متغير بهعنوان يارامترهاى مؤثر بر توليــ اوليسه انتخــاب

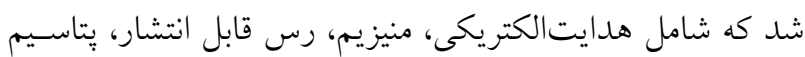

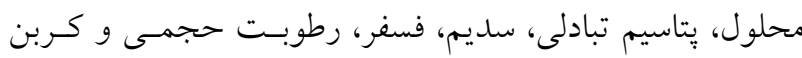

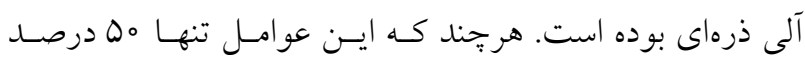

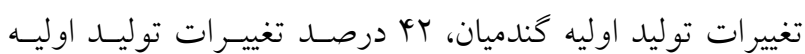


جدول V. مقادير بردار ويثزه مربوط به متغيرهاى تأثير گذار در هر يك از مؤلفها در روش PCA

\begin{tabular}{|c|c|c|c|c|c|c|}
\hline 9 & 0 & 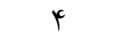 & r & r & 1 & مؤلفه \\
\hline $0 / 090$ &.$/$ rar & $-0 / 019$ & $0 / 019$ & $-0 / 040$ & $-0 / 419$ & كربن آلى ذرهاى \\
\hline$\circ / 009$ & $0 /$ TqY & $-0 / 090$ &.$/ 011$ & -o/okt & $-0 / 410$ & ماده آلى ذرهاى \\
\hline$-0 / T V I$ & -o/TYY & $-\circ / 0 \mu \wedge$ & $0 / 199$ & $-0 / 1 \wedge r$ & $-\circ / \Gamma \Delta \Delta$ & كربن آلى \\
\hline$-0 / T V M$ & -O/YTQ & $-0 / 0{ }^{\prime} \Lambda$ &.$/ 194$ & $-0 / 1 \wedge \mid$ & $-\circ / \pi \Delta \Delta$ & ماده آلى \\
\hline$\circ / \varphi_{0}$ & $-0 / 014$ & -O/TYM & ./०1r & $0 / 494$ & $-0 / 190$ & شن \\
\hline$-0 / T \wedge$ & $\circ / \circ \wedge \Lambda$ &.$/ 199$ & $\circ / 1 \circ 0$ & $-0 /$ MG & o/rar & سيلت \\
\hline $0 / 191$ & $-0 / 1 r q$ & $\circ / \circ \wedge r$ & $-0 /$ TYq & ו וח & $-0 / Y I V$ & رس \\
\hline ०/1AG & - & $\circ / T \circ \Delta$ &.$/ 14 V$ & $-0 / 799$ & $\circ / T \Delta Q$ & اسيديته \\
\hline$-0 / 419$ & $-0 / 014$ & $-0 / 099$ & $-\circ / 4 \wedge 。$ & $-0 / I V V$ & -0/0rt & يتاسيم محلول \\
\hline $0 / 04 \wedge$ & $-0 / 119$ & ( ) & $0 / 4 r V$ & $0 / 1 \mu^{4}$ & $0 / 09 r$ & فسفر \\
\hline$-0 / \pi \circ q$ & $-0 / 011$ & $0 / 499$ & o/ror & OTYG & $-0 / 0 \vee \wedge$ & هدايت الكتريكى \\
\hline$-0 / I V Y$ & $\circ / \backslash \wedge \mid$ & O/TAK & $0 / 79 \Lambda$ & .1199 & $-0 / 111$ & آهك \\
\hline$-0 / 10 V$ & $-\circ / \circ \circ Y^{x}$ & $0 / 49 V$ & $-0 / 04 \lambda$ & O/YYI & $-0 / 1 \vee q$ & كلسيم \\
\hline$-0 / 11 \mu$ & - MUT & $0 / 401$ & $-0 / 094$ & ०/TVT & - O/०YY & سلديم \\
\hline$-0 / I V Q$ & $-0 / 14 \wedge$ & - O/TGY & \%०VG & $\circ / \circ \Delta 4$ & ०/NY & رطوبت حجمى \\
\hline (r/אים & - MANF & $-0 / 0 \vee 9$ & O/YYY & - & $-0 / 114$ & يتاسيم تبادلى \\
\hline$-0 / 090$ & $-0 / 194$ & $\circ / 1 \wedge \circ$ & $-0 / r \wedge \circ$ & $-0 / 041$ & $\circ / \circ \wedge k$ & منيزيم \\
\hline$-o / \mu Y_{0}$ & $0 / \pi 19$ & $-0 / 19 r$ & L & o/l1r & $\circ / T \Delta \wedge$ & س قابل انتشار \\
\hline
\end{tabular}

عو امل زيستى، بهويزه عوامل وابسته بـهـ انسـان مانــــ مــديريت

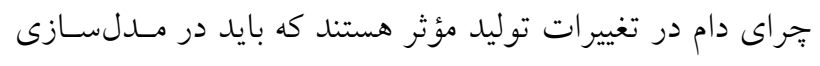
تغييرات توليد مد نظر قرار كيرند. بهعلاوه در اين يزوهش تنهـا

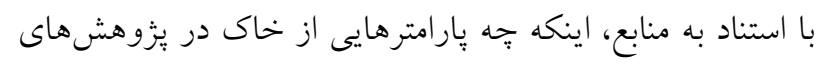

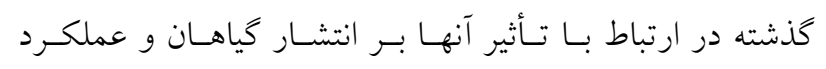
اكوسيستم مد نظر قرار كرفته بودهاند، انتخاب شــند و احتمـالاً يار امترهاى ديخرى از خاك در عملكرد اكوسيستم مـؤثر هسـتند

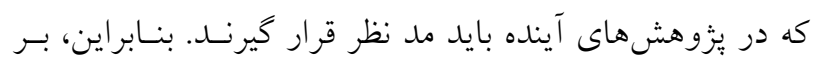

كم تغييرات براى اين متغيرها در منطقه مـورد مطالعـه مـانع از بروز اثر قابل ملاحظهاى روى توليد اوليه شده اسـت. هم:جنسين،

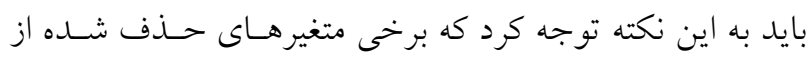

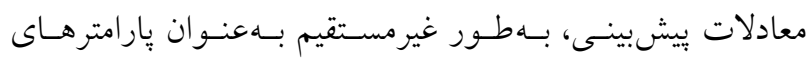
خاكسازى (اثرات متقابل متغيرها) اثر خود را روى ويزگى هـاى خاك و بهتبع آن روى توليدات گياهى داشتهاند. همجنين، انتشار

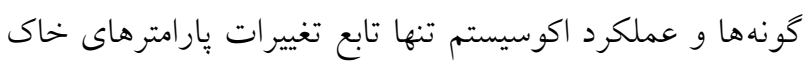

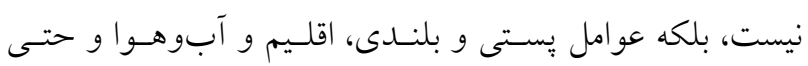


تبادلى و يتاسيم محلول و فسفر بـود. زاو و همكـاران (MY) نيـز

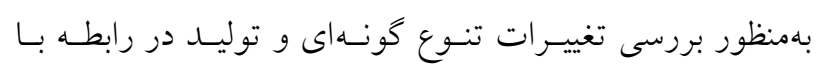

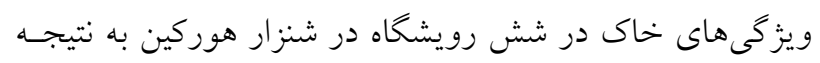

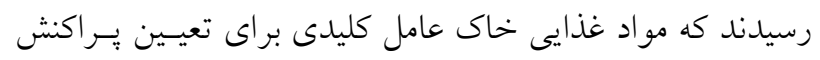
و الخوى تيبٍهاى گياهى اصلى منطقه و توليد هستند.

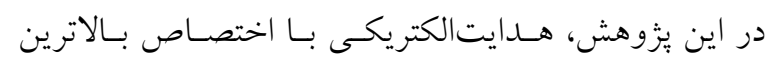

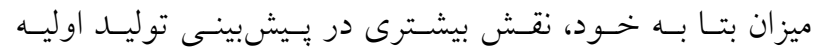

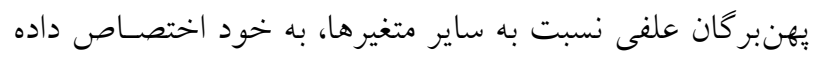

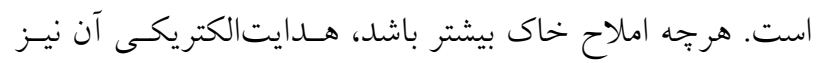

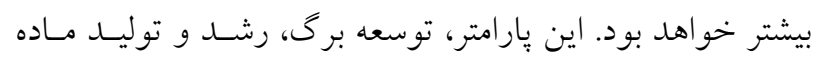

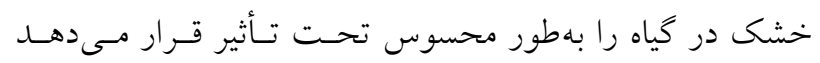

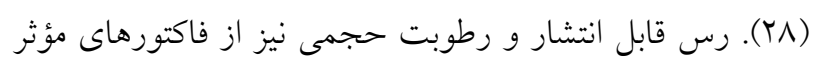
بر بهنبر گان علفى بودند.

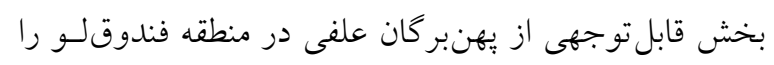

Trifolium repense L. و Trifolium pratense L. تشكيل مىدهند كه يكى عامل زيستى بالقوه در تثبيـت نيتـروزن ونان

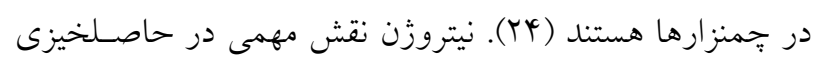

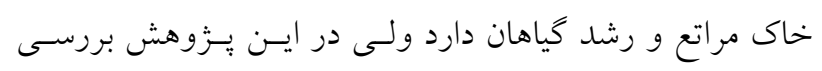

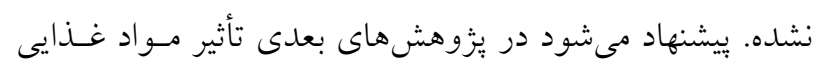

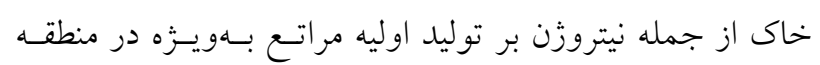

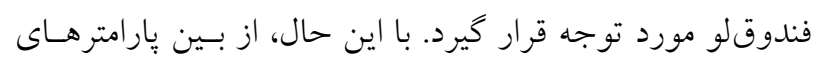

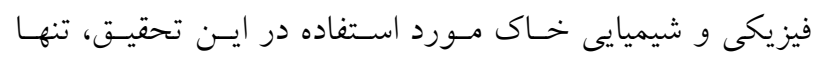

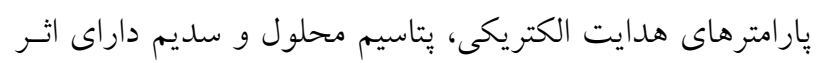

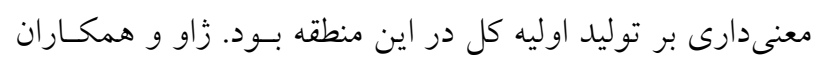

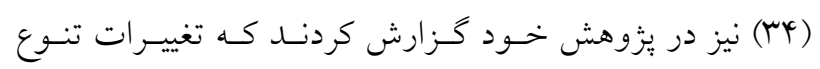

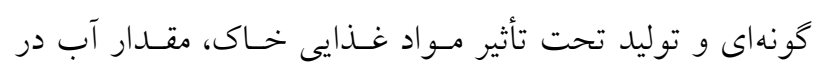

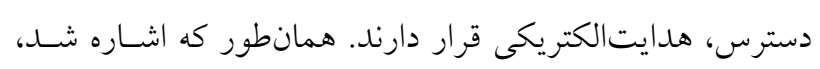

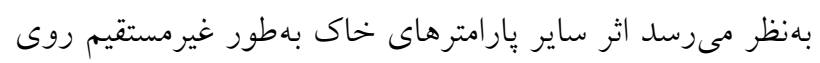

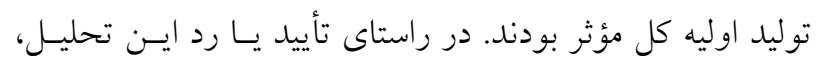

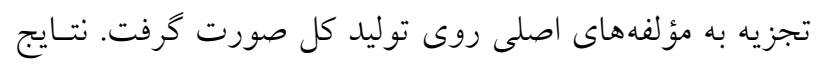
نشان داد كه كربن آلى ذرهاى، ماده آلى ذرهاى، كربن آلى و مولى ماده

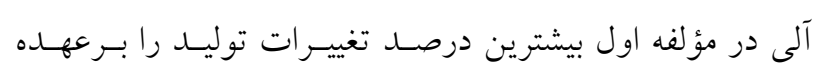

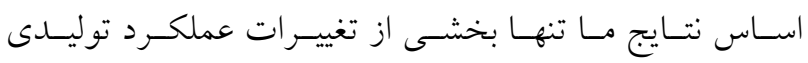

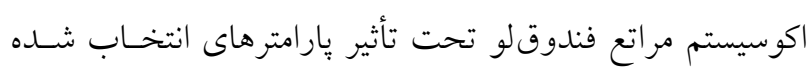

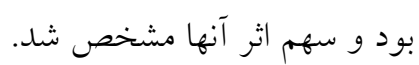

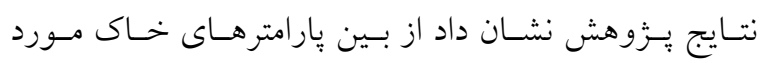

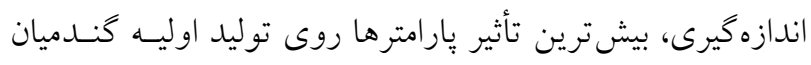

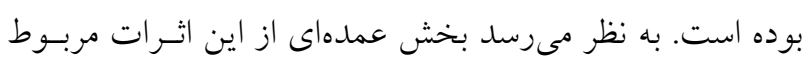

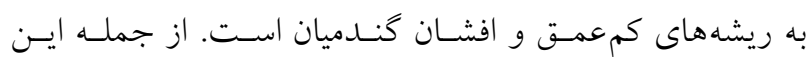

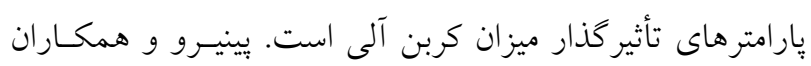

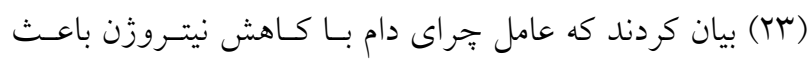

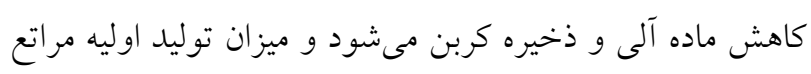

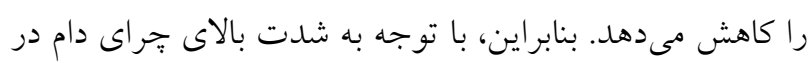

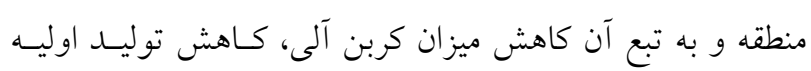

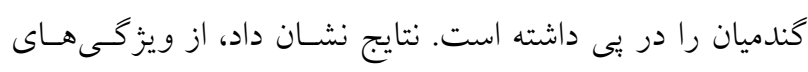
فيزيكى خاى، تنها رس قابل انتشار بر توليد گُندميان مؤثر است.

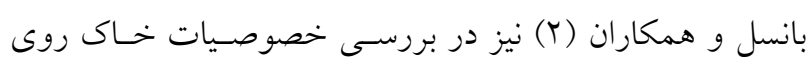

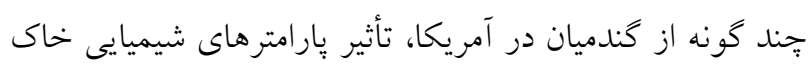

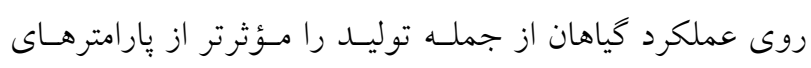

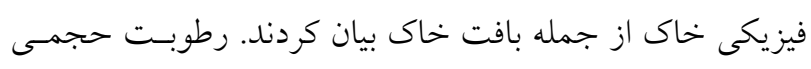

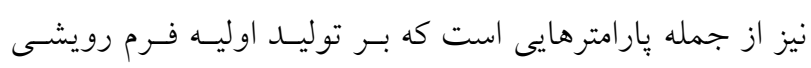

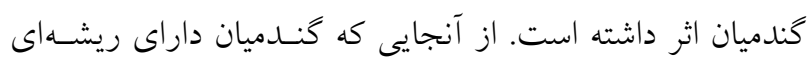

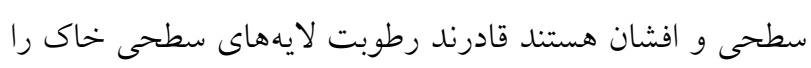

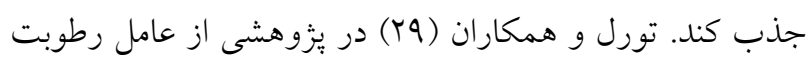

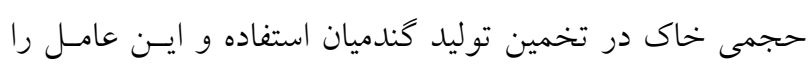

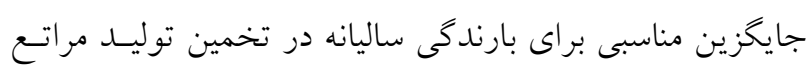

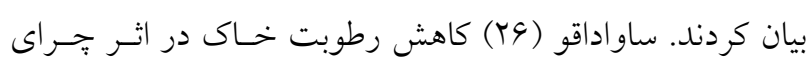

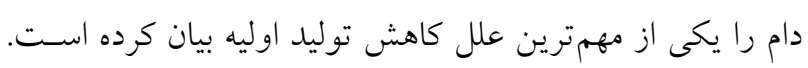

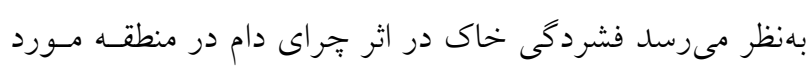

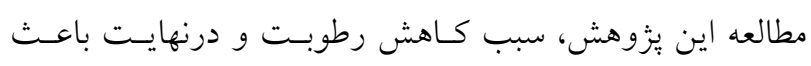

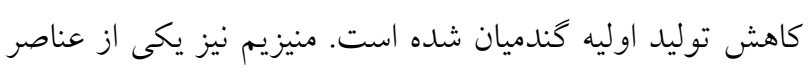

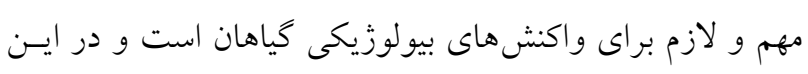
يزوهش، در كنار سديم، از متغيرهاى تأثير گذار بر توليد كندميان

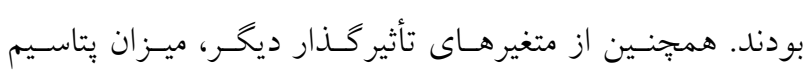




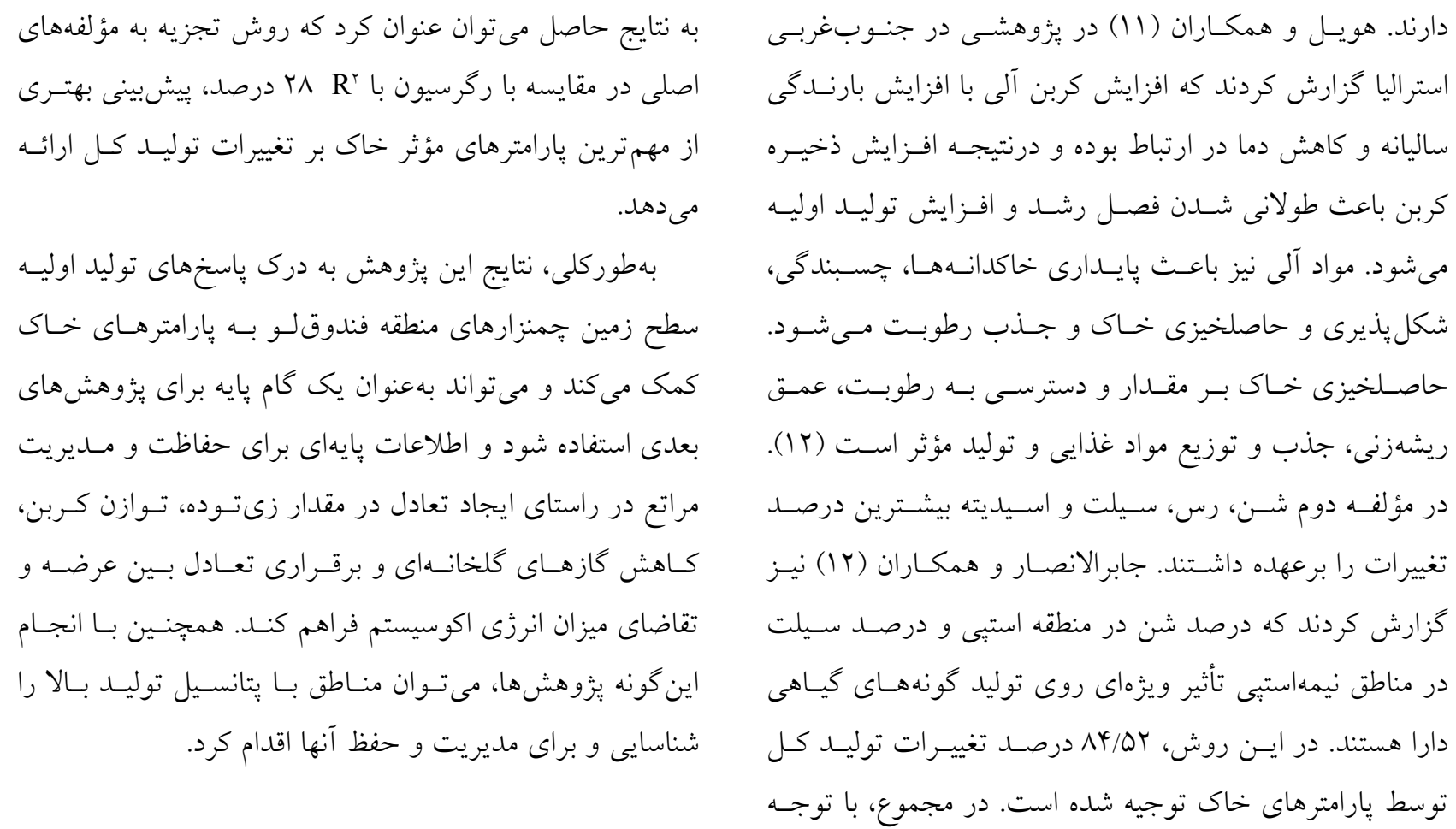

منابع مورد استفاده

1. Andales, A. A., J. D. Derner, L. R. Ahuja and R. H. Hare. 2006. Strategic and tactical prediction of forage production in northern mixed-grass Prairie. Rangeland Ecology \& Management 59: 576-584. https://doi.org/10.2111/06-001R1.1.

2. Bansel, Sh., J. J. James and R. L. Sheley. 2014. The effects of precipitation and soil type on three invasive annual grasses in the western United States, Journal of Arid Environments 104: 38-42. https://doi.org/10.1016/j.jaridenv.2014.01.010

3. Brinkley, D. and C. Giardina. 1998. Why do tree species affect soils? The warp and woof of tree-soil interactions. Biogeochemistry 42(1-2): 89-106.

4. Bouyoucos, G. J. 1962. Hydrometer method improved for making particle size analyses of soils. Agronomy Journal 54(5): 464- 465.

5. Burt, R. 2004. Soil Survey Laboratory Methods Manual. 735 P. Version 4.0. Soil Survey Investigation Report No 42, U.S. Government Print.

6. Dadjou F. 2017. The effect of the factors affecting production in the highlands of Hir and Neor using ground-based and remotely sensed methods, MSc. Thesis, The University of Mohaghegh Ardabili, Ardabil, Iran. (In Farsi).

7. Elmojahid, L., X. Leroux, S. Michalet, F. Bellvert, A. Weigelt and F. Poly. 2017. Effect of plant diversity on the diversity of soil organic compounds. PLoS ONE 12(2): e0170494. https://doi.org/10.1371/journal.pone.0170494.

8. Fakhar Izadi N., K. Naseri and M. Mesdaghi. 2016. The effects of plot size and shape on accuracy and precision of estimation of production at some pastures by sampling simulation. Iranian Journal of Applied Ecology (14): 51-60. (In Farsi).

9. Goharnejad, A., A. Zarei and P. Tahmasebi. 2014. Comparing multiple regressions, principal component analysis, partial least squre regression, ridge regression, and ridge regression in predicting rangeland biomass in the semi steppe rangeland of Iran, Environment and Natural Resources Journal 12(1): 1-21.

10. Ghorbani, A., J. Sharifi, H. Kavianpoor, B. Malekpoor and F. Mirzaei AghcheGheshlagh. 2013. Investigation on ecological characteristics of Festuca ovina L. in south-eastern rangelands of Sabalan. Iranian Journal of Range \& Desert Research 20(2): 379-396. (In Farsi).

11. Hoyle, F. C., R. A. Oleary and D. V. Murphy. 2016. Spatially governed climate factors dominate management in determining the quantity and distribution of soil organic carbon in dry land agriculture systems. Scientific Reports 6 : 1-12. https://doi.org/10.1038/srep31468 
12. Jaberalansar Z., M.Tarkesh Esfahani, M. Basiri and S. Pourmanafi. 2017. Effects of environmental factors on forage production of Steppe and semi Steppe rangelands in western part of Isfahan province. Iranian Journal of Rangeland 10(3): 302-314. (In Farsi).

13. Jackson, M. A. 1962. Soil Chemical Analysis. Constable and Co Ltd, London.

14. Jackson, D. A. 1993. Stopping in principal components analysis: a comparison of heuristical and statistical approaches. Ecology 74: 2204-2214.

15. Jones, J. B. 2001. Laboratory Guide for Conducting Soil Tests and Plant Analysis. Boca Raton, D.C.CRC Press, London, New York and Washington.

16. Kent, M. and P. Coker. 1992. Vegetation Description and Analysis. John Wiley \& Sons, England.

17. Lal, R. 1994. Data analysis and interpretation. In: Methods and Guidelines for Assessing Sustainable Use of Soil and Water Resources in the Tropics, R. Lal (Ed.). Soil Management Support Services Technical. Monograph. No. 21. SMSS/SCS/USDA, Washington D.C, pp. 59-64.

18. Magharri, E., S. M. Razavi, E. Ghorbani, L. Nahar and S. D. Sarker. 2015. Chemical composition, some allelopathic aspects, free-radical-scavenging property and antifungal activity of the volatile oil of the flowering tops of Leucanthemum vulgare Lam. Records of Natural Products 9(4): 538-545.

19. Mirzaei Mossivand, A., A. Ghorbani, M. A. Zare Chahoki, F. Keivan Behjou and K. Sefidi. 2016. Environment factors affecting the distribution of species Prangos ferulacea Lindl. in rangelands of Ardabil Province. Iranian Journal of Rangeland 10(2): 191-203. (In Farsi).

20. Murphy, J. and P. Riley. 1988. A modified single solution method for determination of phosphate in natural water. Pp: 31-36, In: Page, E. L., R. H. Miller and R. D. Keeney (Ed.), Methods of Soil Analysis. Part. 2. Chemical and microbiological properties. American Society of Agronomy. Inc. Soil Science Society of America Publisher, WI.

21. Nelson, D. W. and L. E. Sommers. 1996. Total carbon, organic carbon, and organic matter. PP. 153-188. In: Sparks, D. L. (Ed.), Methods of Soil Analysis, Part 3: Chemical Methods. SSSA Book Series Number 5, Soil Science Society of America. J, Madison, WI.

22. Page, A. L. 1992. Methods of Soil Analysis. ASA and SSSA Publishers: Madison, WI.

23. Pineiro, G., J. M. Paruedo, M. Oesterheld and E. G. Jobbagy. 2010. Pathways of grazing effects on soil organic carbon and nitrogen. Rangeland Ecology \& Management 63(1): 109-119. https://doi.org/10.2111/08-255.1.

24. Rasmussen, J., K. Søegaard, K. Pirhofer-Walzl and J. Eriksen. 2012. $\mathrm{N}_{2}$ - fixation and residual N effect of four legume species and four companion grass species. European Journal of Agronomy 36: 66-74. https://doi.org/10.1016/j.eja.2011.09.003.

25. Rocarpian, P., S. Gachet, K. Metzner and A. Saatkamp. 2016. Moisture and soil parameters drive plant community assembly in Mediterranean temporary pools. Hydrobiologia 781(1): 55-66.

26. Savadogo, P., L. Sawadogo and D. Tiveau. 2007. Effects of grazing intensity and prescribed fire on soil physical and hydrological properties and pasture yield in the savanna woodlands of Burkina Faso. Agriculture, Ecosystems \& Environment 118: 80-92. https://doi.org/10.1016/j.agee.2006.05.002

27. Schroder, T. and F. D. Fleig. 2017. Spatial pattern and edge effects on soil organic matter and nutrients in a forest fragment of southern Brazil. Soil Research 55(7): 649-656.

28. Tawfik, A. and A. Noga. 2001. Priming of Cumin (Cuminum cyminum) seeds and its effects of germination, emergence and storability. Journal of applied botany 75: 216-220.

29. Torell, L. A., K. C. McDaniel and V. Koren. 2011. Estimating grass yield on blue grama range from seasonal rainfall and soil moisture measurements. Rangeland Ecology and Management 64(1): 56-66. https://doi.org/10.2111/REM-D-09-00107.1 .

30. Valizadeh Yonjalli, R., F. Mirzaei Aghjehgheshlagh and A. Ghorbani. 2015. Comparing rangeland soil- vegetation mineral content based on elevation classes and phenological stages in north-facing slopes, Sabalan region, Ardabil Province. Iranian Journal of Water \& Soil Science 73: 233-247. (In Farsi).

31. Vallentine, J. F. 1990. Grazing Management. Academic Press. San Diego, CA, USA.

32. Yu, M. M., Y. H. Chen, Z. B. Zhu, L. Liu, L. X. Zhang and Q. S. Guo. 2016. Effect of phosphorus supply on plant productivity, photosynthetic efficiency and bioactive-component production in Prunella vulgaris L. under hydroponic condition. Journal of Plant Nutrition 39(12): 1672-1680. https://doi.org/10.1080/01904167.2016.1161785.

33. Zareh Hesari, B., A. Ghorbani, F. Azimi Motam, K. Hashmi Majd and A. Asghari. 2014. Study the effective ecological factors on distribution of Artemisia fragrans in southeast faced slopes of Sabalan, Iranian Journal of Rangeland 8(3): 238-250. (In Farsi).

34. Zhao, W. Y., J. L. Li and J. G. Qi. 2007. Changes in vegetation diversity and structure in response to heavy pressure in the northern Tianshan Mountion, China. Journal of Arid Environments 68: 465-479. https://doi.org/10.1016/j.jaridenv.2006.06.007. 


\title{
Effects of Soil Parameters on Aboveground Net Primary Production in Meadow Rangelands in Fandoghlou Region of Namin County, Ardabil Province
}

\author{
A. Ghorbani1 ${ }^{*}$, E. Hassanzadeh Kuhsareh ${ }^{1}$, M. Moameri ${ }^{1}$, K. Hashemi Majd ${ }^{2}$ \\ and A. Pournemati ${ }^{3}$
}

(Received: November 16-2018; Accepted: October 24-2018)

\begin{abstract}
In this study, the effect of some soil parameters on the life forms and total aboveground net primary production (ANPP) in meadow rangelands in Fandoghlou region of Namin county in Ardabil Province were investigated. ANPP in 180 plots of 12 by harvesting and weighting method were measured. Eighteen soil samples were collected along transects. Some physical and chemical attributes of the soil were measured by standard methods. The relationship between these parameters and ANPP was performed using multivariate regression (enter) method. To determine the effects of important soil parameters on ANPP variation, principal component analysis (PCA) was used. The results of regression analysis showed that electrical conductivity (EC), magnesium (Mg), spreadable clay (WDC), volumetric moisture content (VM), organic carbon (OC), soluble potassium (KS), exchangeable potassium (Kexch), sodium (Na) and phosphorus (P) were the effective parameters on the life forms and total ANPP $(\mathrm{p}<0.01)$. The accuracy of obtained equations for grasses, forbs and total ANPP were calculated 79, 76 and 70\%, respectively. Moreover, results of PCA showed that soil parameters justify 84.52 percent of total ANPP variation and in comparison, with regression results with $28 \%$ it provides better results.
\end{abstract}

Keywords: Production modelling, Biomass, Life form, Soil parameters, Meadow rangelands, Namin county

1. Department of Natural Resources, Faculty of Agriculture and Natural Resource, University of Mohaghegh Ardabili, Ardabil, Iran.

2. Department of Soil Science, Faculty of Agriculture and Natural Resource, University of Mohaghegh Ardabili, Ardabil, Iran.

3. Department of Natural Resources, Faculty of Agriculture and Natural Resources, University of Gorgan University of Agriculture Science and Natural Resources, Gorgan, Iran.

*: Corresponding Author, Email: a_ghorbani@uma.ac.ir 